\title{
Psychiatric problems and suicidal behaviour in incarcerated adolescents in the Islamic Republic of Iran
}

\author{
A. Ghanizadeh, ${ }^{1,2}$ S.Z. Nouri ${ }^{2}$ and S.S. Nabi ${ }^{2}$
}

$$
\begin{aligned}
& \text { الاضطر ابات النفسية والسلوك الانتحاري لدى المر اهقين المحتَجزين في جمهورية إيران الإسلامية }
\end{aligned}
$$

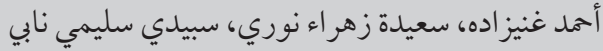

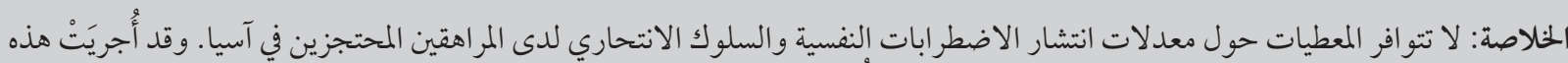

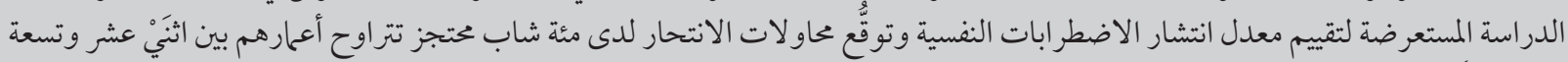

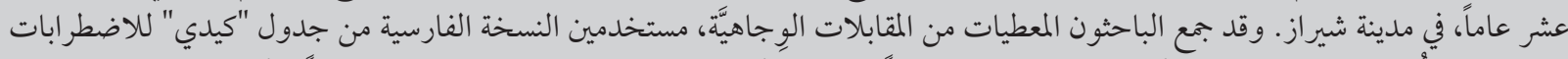

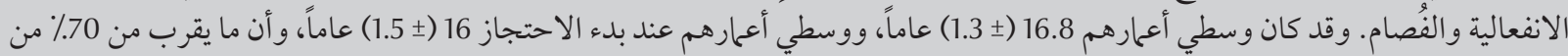

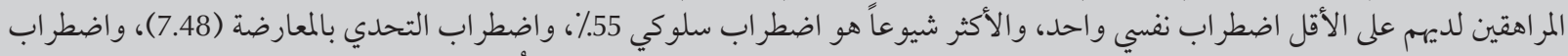

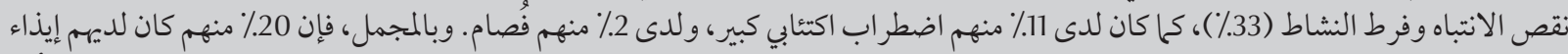

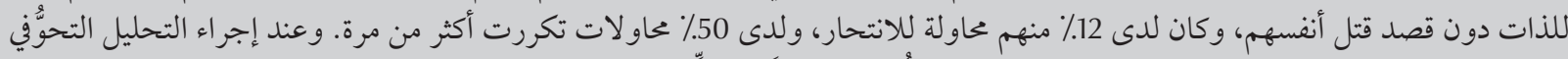

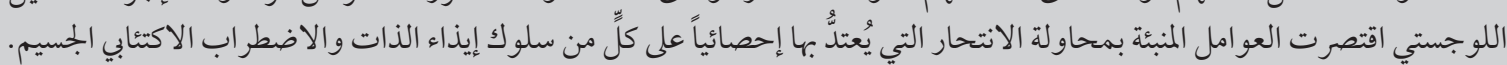

ABSTRACT Data are lacking about the prevalence of psychiatric disorders and suicidal behaviour in incarcerated adolescents in Asia. This cross-sectional study evaluated the prevalence of psychiatric disorders and the prediction of suicidal attempts in 100 incarcerated males aged 12-19 years in Shiraz. Data were collected in face-to-face interview using the Kiddie Schedule for Affective Disorders and Schizophrenia (Farsi version). The mean age was 16.8 (SD 1.3) years and mean age at first imprisonment was 16.0 (SD 1.5) years. Nearly $70 \%$ of the adolescents had at least one current psychiatric disorder, the commonest being: conduct disorder (55\%), oppositional defiant disorder (48\%) and attention deficit hyperactivity disorder (33\%); $11 \%$ had major depressive disorder and $2 \%$ schizophrenia. In all, $20 \%$ had self-harmed without intent to kill themselves and $12 \%$ had attempted suicide, $50 \%$ of whom had tried more than once. In logistic regression analysis only self-harming behaviour and major depressive disorder were significant predictors of attempted suicide.

\section{Problèmes psychiatriques et comportement suicidaire des adolescents incarcérés en République islamique d'Iran}

RÉSUMÉ Les données sont rares au sujet de la prévalence des troubles psychiatriques et du comportement suicidaire des adolescents incarcérés en Asie. La présente étude transversale a évalué la prévalence des troubles psychiatriques et le risque de tentatives de suicide chez 100 garçons âgés de 12 à 19 ans incarcérés à Chiraz. Les données ont été recueillies lors d'entrevues individuelles à l'aide de la version en langue farsi du questionnaire Kiddie Schedule for Affective Disorders and Schizophrenia. L'âge moyen des participants était 16,8 ans (écart type 1,3) et ils avaient 16,0 ans en moyenne (écart type 1,5) lors de leur premier séjour carcéral. Près de $70 \%$ des adolescents souffraient d'au moins un trouble psychiatrique courant. Les plus fréquents étaient les suivants : trouble du comportement (55\%), trouble oppositionnel avec provocation (48\%) et trouble déficitaire de l'attention avec hyperactivité (33\%) ; $11 \%$ souffraient de dépression sévère et $2 \%$ étaient atteints de schizophrénie. Au total, $20 \%$ s'étaient automutilés sans intention de se donner la mort et $12 \%$ avaient tenté de se suicider. Parmi ceux-ci, $50 \%$ avaient fait plusieurs tentatives. Selon l'analyse de régression logistique, seuls les comportements d'automutilation et la dépression sévère étaient des facteurs prédictifs importants d'une tentative de suicide. 


\section{Introduction}

The Islamic Republic of Iran has a very high proportion of young people; about $33 \%$ of its population is below 20 years of age. About $90 \%$ of the studies on adolescents in juvenile detention come from the United States of America (USA) [1]. A systematic review and meta-regression analysis of 25 surveys found that nearly all of them reported that over two-thirds of the adolescents suffered from psychiatric disorders [1]. Rates in other studies in the USA, Canada and Europe are also high (Table 1) [2-6]. Specifically the systematic review indicated that the rate of psychotic illness, manic episodes, major depression, attention deficit hyperactivity disorder (ADHD) and conduct disorder in adolescents in detention and correctional facilities were $3.3 \%, 3.1 \%, 10.6 \%, 11.7 \%$ and $52.8 \%$ respectively $[1]$.

Studies from other parts of the world are few. No studies from Asia that investigated different psychiatric disorders in incarcerated adolescents were found. A study on psychiatric disorders in adult prisoners in the Islamic Republic of Iran reported that the rates of lifetime and current psychiatric disorders were $88 \%$ and $57 \%$ respectively [7].

Many previous studies have relied on medical records [8] and selfcompleted questionnaires and have not assessed different psychiatric disorders [9], or they studied mental distress rather than psychiatric disorders [10]. Some of the studies have used DISC, a highly structured instrument, to assess psychiatric disorders [2] although it has been indicated that some disorders such as ADHD and depression are under-reported using DISC [1].

To the best of our knowledge, this is the first study in Asia and the Islamic Republic of Iran that investigated the prevalence of psychiatric disorders and suicidal behaviour in the incarcerated adolescents. The present study tries to fill this gap in the literature. Assessment of psychiatric problems of incarcerated adolescents is essential for their management and treatment. The aims of this study were to assess the prevalence of psychiatric disorders and the prediction of suicidal attempts in incarcerated adolescents in Shiraz, Southern Islamic Republic of Iran.

\section{Methods}

\section{Study sample and setting}

This was a cross-sectional study conducted in Adel Abad (Kanoon e Eslah Va Tarbiat) Prison, which is the only prison in Shiraz. Subjects of the present study were a convenience sample of 100 boys aged $<20$ years incarcerated in the prison from July 2006 to April 2008. Individuals older than 19 years were not included.

\section{Data collection}

The adolescents were interviewed by 2 of the authors using the Farsi version of the Kiddie Schedule for Affective Disorders and Schizophrenia (K-SADS) [11].

$\mathrm{K}-S A D S$ is a semi-structured interview based on DSM-IV diagnostic criteria [12]. Many different psychiatric disorders are evaluated by K-SADS, such as major depressive disorder, psychosis, bipolar disorder, obsessive-compulsive disorder, separation anxiety disorder, generalized anxiety disorder, panic disorder, social phobia, agoraphobia and specific phobia, tic disorder, attention deficit hyperactivity disorder, disruptive behavioural disorder, anorexia and

\begin{tabular}{|c|c|c|c|}
\hline Study & Sample & Instrument & Results \\
\hline Baltimore, USA [5] & $\begin{array}{l}120 \text { referred incarcerated } \\
\text { youth }\end{array}$ & $\begin{array}{l}\text { Diagnostic Interview Schedule for } \\
\text { Children and the Child Behavior } \\
\text { Checklist }\end{array}$ & $\begin{array}{l}96 \% \text { had at least } 1 \\
\text { psychiatric disorder }\end{array}$ \\
\hline Illinois, USA [3] & $\begin{array}{l}1172 \text { boys, } 657 \text { girls, aged } 10- \\
18 \text { years who were arrested } \\
\text { and detained }\end{array}$ & $\begin{array}{l}\text { Diagnostic Interview Schedule for } \\
\text { Children version } 2.3\end{array}$ & $\begin{array}{l}40 \% \text { of boys had at least } 1 \\
\text { disorder }\end{array}$ \\
\hline Canada [4] & 49 incarcerated adolescents & $\begin{array}{l}\text { Diagnostic Interview for Children } \\
\text { and Adolescents Revised } \\
\text { (DICA-R) }\end{array}$ & $\begin{array}{l}63.3 \% \text { had } 2 \text { or more } \\
\text { psychiatric disorders }\end{array}$ \\
\hline Belgium [15] & 72 delinquent adolescents & $\begin{array}{l}\text { Semi-structured assessment } \\
\text { (Child Assessment Schedule) and } \\
\text { self-report measures }\end{array}$ & $\begin{array}{l}70 \% \text { had at least } 1 \\
\text { psychiatric diagnosis }\end{array}$ \\
\hline Denmark [6] & $\begin{array}{l}100 \text { incarcerated boys aged } \\
15-17 \text { years }\end{array}$ & $\begin{array}{l}\text { Interviewed using ICD-10 } \\
\text { diagnostic criteria }\end{array}$ & $\begin{array}{l}69 \% \text { had "any mental } \\
\text { disorder"; } 2 \% \text { had } \\
\text { schizophrenia }\end{array}$ \\
\hline Netherlands [2] & $\begin{array}{l}204 \text { incarcerated boys aged } \\
12-18 \text { years }\end{array}$ & $\begin{array}{l}\text { Diagnostic Interview Schedule for } \\
\text { Children (DISC) }\end{array}$ & $\begin{array}{l}90 \% \text { had at least } 1 \\
\text { psychiatric disorder }\end{array}$ \\
\hline
\end{tabular}


bulimia nervosa, and enuresis. It has been used in several studies in the Islamic Republic of Iran $[13,14]$.

Subsyndromal episodes include the presence of 2 or more key symptoms of the disorder but the symptoms do not present severely enough to lead to the diagnosis of the disorder or they have not met full diagnostic criteria according to DSM IV. The validity, reliability, sensitivity and specificity of the Farsi version have been documented [11].

The adolescents were interviewed face to face individually in the prison by 2 of the authors (SZN and SSN).

\section{Ethical issues}

The study was approved by the Deputy of Research Affairs of Shiraz University of Medical Sciences. In addition the authorities of the prison gave permission to conduct the study which was done in accordance with the Declaration of Helsinki as revised in 1996 (http://www.wma.net/ en/30publications/10policies/b3/index.html). Before starting the interview, we informed the adolescents about the aim of our research and gave them the option to participate or not and to withdraw whenever they wanted. The participants were assured that the answers would be confidential. All agreed to participate and gave their verbal informed consent; none dropped out during the study.

If a respondent had an acute psychiatric problem, with his permission, the authorities were informed and advised.

\section{Data analysis}

Data were analysed using SPSS for Windows, version 14. Descriptive analysis was conducted to examine the frequency of the disorders. Binary logistic regression analysis was used to determine the probable predictors of attempted suicide. The co-occurrence of psychiatric disorders, including ADHD, conduct disorder, oppositional defiant disorder, self-harm behaviour, and major depressive disorder and tobacco use, was considered as a possible independent predictor of suicidal behaviour.

\section{Results}

The sociodemographic characteristics of the adolescents and their parent are shown in Table 2. The mean length of their current imprisonment was 172 (SD 191.6) days with a range of 30 to 730 days. The mean of the number of times which they had been incarcerated was 1.35 (SD 0.72) times with a range of 1-4 times.

As regards birth order, $32 \%$ of the adolescents were the last child in the family and 29\% were the first. For 20\% of the adolescents, their father was dead and for $11 \%$ their mother had died. As regards parental employment, $10 \%$ of the fathers were unemployed and the others were mostly unskilled worker, while the majority of the mothers were housewives. The mean age at first imprisonment was 16.0 (SD 1.5) years and $23 \%$ of the adolescents had been imprisoned more than once. The causes of first time imprisonment (self-reported by 77 of the sample) were non-armed robbery (43.4\%) and fighting (39.1\%), but 33\% of the adolescents did not report why they had been imprisoned the first time. The reasons for their current imprisonment were robbery (26\%), murder (23\%), fighting (21\%), other, such as drug dealing (16\%), and kidnapping (14\%).

In all, $12 \%$ reported a positive history of attempted suicide and 50\% with a positive history of attempted suicide had tried more than once. The mean age at the first suicide attempt was 15.7 (SD 1.7) years, range 12-17 years. Only $1 \%$ of the sample reported a positive family history of suicide. Of the whole sample, 20\% reported that they had injured themselves without intent to kill themselves.

The commonest disorders found were: conduct disorder 55\%, oppositional defiant disorder 48\%, ADHD 33\% and major depressive disorder 11\%; schizophrenia was diagnosed in 2\% (Table 3). There were no cases of bipolar disorder, panic disorder, separation anxiety disorder, generalized anxiety disorder, social phobia, agoraphobia, anorexia and bulimia nervosa, enuresis or encopresis.

Some participants did not fulfil all the diagnostic criteria for a disorder but had at least 2 major key symptoms of the disorder. These were considered subsyndromal cases. The commonest subsyndromal disorders were: ADHD $27 \%$, major depressive disorder $24 \%$, post-traumatic stress disorder $20 \%$, generalized anxiety disorder $18 \%$, social phobia $16 \%$, oppositional defiant disorder $14 \%$, separation anxiety disorder $12 \%$ and conduct disorder $11 \%$ (Table 3).

The life-time (excluding the past year) prevalence for ADHD was $72 \%$, for oppositional defiant disorder it was $55 \%$, for conduct disorder it was $52 \%$, and for enuresis it was 12\% (Table 4).

On binary logistic regression the only significant predictors of suicide attempt were self-harm behaviour $(P$ $<0.001)$ and major depressive disorder $(P=0.034)$. None of the other disorders predicted attempted suicide (Table 5).

\section{Discussion}

Our results show that the prevalence of some psychiatric disorders and symptoms in our sample of adolescent prison inmates was high. Over half of them suffered from conduct disorder and one-third had ADHD. We had no control group with which to compare our results.

To the best of our knowledge, this is the first study to evaluated the prevalence of different psychiatric disorders using face-to-face interview in incarcerated adolescents in a non-Western country. There are no published data 


\begin{tabular}{|c|c|}
\hline Variable & Value \\
\hline \multicolumn{2}{|l|}{ Adolescents } \\
\hline \multicolumn{2}{|l|}{ Age and education } \\
\hline Mean age (SD) in years & $16.7(1.28)$ \\
\hline Age range (years) & $12-19$ \\
\hline Mean (SD) years of education & $6(3.29)$ \\
\hline Year of education range & $0-12$ \\
\hline \multicolumn{2}{|l|}{ Family income (rials): \% reporting: } \\
\hline $2000000-4000000$ & 28 \\
\hline$>4000000$ & 10 \\
\hline$<2000000$ & 58 \\
\hline Mean (SD) number of siblings & $5.30(2.71)$ \\
\hline Range of number of siblings & $1-14$ \\
\hline \multicolumn{2}{|l|}{ Birth order: \% } \\
\hline 1 & 29 \\
\hline Middle & 39 \\
\hline Last & 32 \\
\hline Mean (SD) age at first imprisonment in years & $16.05(1.50)$ \\
\hline Imprisoned $>1$ time $(\%)$ & 23 \\
\hline \multicolumn{2}{|c|}{ Main reported reason for first imprisonment $(\%)(n=77)$} \\
\hline Non-armed robbery & 43.4 \\
\hline Fighting & 39.1 \\
\hline Drug dealing & 8.7 \\
\hline Drunkenness & 4.3 \\
\hline Other (e.g. drug dealing) & 4.3 \\
\hline \multicolumn{2}{|l|}{ Reason for their current imprisonment } \\
\hline Robbery & 26 \\
\hline Murder & 23 \\
\hline Fighting & 21 \\
\hline Kidnapping & 14 \\
\hline Other (e.g. drug dealing) & 16 \\
\hline \multicolumn{2}{|l|}{ Parents } \\
\hline \multicolumn{2}{|l|}{ Deceased } \\
\hline Mean (SD) years of mother's education & $3.60(4.44)$ \\
\hline Father dead & 20 \\
\hline Mother dead & 11 \\
\hline \multicolumn{2}{|l|}{ Father's occupation } \\
\hline Unemployed & 10 \\
\hline Unskilled worker & 21 \\
\hline Other & 69 \\
\hline \multicolumn{2}{|l|}{ Mother's occupation } \\
\hline Housewife & 77 \\
\hline Unskilled worker & 8 \\
\hline Other & 15 \\
\hline
\end{tabular}

$S D=$ standard deviation. from the Islamic Republic of Iran to compare our results with.

There have been many studies in non-Asian countries and while there is a considerable variety among the methods used, sample size and the instruments used, there are significant similarities between their results and ours. Not considering subsyndromal group, nearly $70 \%$ of the adolescents in our study had at least 1 current psychiatric disorder: $14 \%$ had 1 disorder (21\% life-time), $28 \%$ had 2 disorders (23\% life-time) and $28 \%$ had 3 or more disorders ( $45 \%$ life-time). These findings are similar or sometimes higher than found in American adolescent detainees $[3,5]$ (Table 1). More than two-thirds of incarcerated adolescents had at least 1 psychiatric disorder [5]. Similar high prevalence rates have been reported from the Netherlands, Canada, Belgium, Denmark and Brazil $[2,4,6,15,16]$, (Table 1). For example, the study from Canada reported that $63 \%$ of incarcerated adolescents had at least 2 psychiatric disorder [4], while the study from the Netherlands reported that $90 \%$ of their subjects had at least 1 disorder [2]. In Brazil the rates were $54 \%$ for ADHD, $77 \%$ for conduct disorder and $41 \%$ for oppositional defiant disorder [16].

There are few studies from Asia. One study in Japan studied only the prevalence of post-traumatic disorder (PTSD) by PTSD Scale. The researchers found that $21 \%$ of the incarcerated youth had a current or past history of full PTSD and 21\% had partial PTSD [9]. In our study, the rate of subsyndromal PTSD was 20\%. A study in Korea that assessed only ADHD in juvenile delinquents found a rate of ADHD of $42.4 \%[17]$. These rates are very similar to those of our study.

It has been reported that knowledge about psychiatric disorders (ADHD) and symptoms among many families and teachers in the Islamic Republic of Iran is so low that they cannot, even if they want to, help their children 


\begin{tabular}{lcc}
\hline $\begin{array}{l}\text { Table } 3 \text { Frequency of current psychiatric disorders and subsyndromes in the } \\
\text { incarcerated adolescents }(\boldsymbol{n}=\mathbf{1 0 0})\end{array}$ & $\begin{array}{c}\text { Current } \\
\text { psychiatric } \\
\text { disorders }\end{array}$ & $\begin{array}{c}\text { Current } \\
\text { subsyndromes }\end{array}$ \\
\hline Disorder & $\%$ & $\%$ \\
Major depressive disorder & 11 & 24 \\
Mania & 0 & 2 \\
Psychosis & 2 & 4 \\
Separation anxiety disorder & 0 & 18 \\
Social phobia & 0 & 16 \\
Generalized anxiety disorder & 0 & 18 \\
Obsessive-compulsive disorder & 9 & 3 \\
Attention deficit hyperactivity disorder & 33 & 27 \\
Panic disorder & 0 & 2 \\
Oppositional disorder & 48 & 14 \\
Conduct disorder & 55 & 11 \\
Agoraphobia & 0 & 3 \\
Tic disorder & 8 & 1 \\
Post-traumatic stress disorder & 0 & 20 \\
Nicotine use & 33 & - \\
\hline
\end{tabular}

[18]. One study in Islamic Republic of Iran suggests that even the knowledge of general practitioners needs to be improved [19]. Many families do not know that hyperactivity may be a symptom of a disorder, or that frequent stealing by a child in the early years of school can be a first symptom of a disorder. In addition, most of the parents of the incarcerated adolescents in our study had a low level of education and likely had no idea what a psychiatric disorder is. Previous studies in the Islamic Republic of Iran have reported that children with ADHD have less organized and more conflicting interpersonal relationships within their family [20] and in a sample of children with

ADHD, it was reported that $48.1 \%$ and $43.0 \%$ of the mothers and fathers respectively suffered from depressive disorder [14]. Thus, adolescents from difficult or uneducated backgrounds may be at greater risk for certain psychiatric disorders or may have little or no support for their condition, which may lead to problems with the law and subsequent incarceration.

The prevalence of $\mathrm{ADHD}$, conduct disorder and oppositional defiant disorder were high in our study (Tables 3 and 4). It has been shown in American studies that adolescents with ADHD and conduct disorder have a history of arrest at an earlier age and have more

\begin{tabular}{|c|c|c|}
\hline \multirow[t]{2}{*}{ Disorder } & Psychiatric disorders & Subsyndromes \\
\hline & $\%$ & $\%$ \\
\hline Enuresis & 12 & 0 \\
\hline ADHD & 72 & 13 \\
\hline Oppositional disorder & 55 & 13 \\
\hline Conduct disorder & 52 & 19 \\
\hline
\end{tabular}

$A D H D=$ attention deficit hyperactivity disorder . total arrest than other children [21,22]. This risk is also higher in the adulthood [21]. In other words, ADHD children have a higher risk of committing crimes and of being arrested and incarcerated [22].

Suicidal behaviour is high among incarcerated adolescents [23]. A study among 271 incarcerated male juvenile delinquents diagnosed with conduct disorder reported that $34 \%$ of them had a lifetime history of either suicidal thoughts or attempts [24]. Young people who have self-harming behaviour have an increased risk of complete suicide and the two are strongly correlated [25]. The rate of attempted suicide in our country is about $1 \%$ among adult males [26]. In our study, 20 (20\%) adolescents had self-harming behaviour, most of whom were repeated self-harmers. Among these, 10 (50\%) individuals had a history of suicide. Thus, overall the frequency of attempted suicide among our sample was $12 \%$, much higher than the $1 \%$ reported among adult males in the Islamic Republic of Iran [26]. In regression analysis, only self-harming behaviour and major depression predicted attempted suicide. The diagnosis, management and treatment of self-harming behaviour and major depression among incarcerated adolescents could help prevent repetition and would be helpful for both the adolescents and juvenile justice system.

\section{Limitations}

There are some limitations to the current study. The sample was chosen from only 1 prison in southern Islamic Republic of Iran and only the axis I disorders were studied and were only assessed using self-reported information. For financial constraints, we were only able to include 100 adolescents who were available for interview during the study period. Therefore, these results cannot be generalized to other prisoners or community samples. We could not also assess a control group from a community sample to compare 


\begin{tabular}{lcc}
\hline \multicolumn{3}{l}{ Table 5 Predictors of suicidal attempt in male adolescents prisoners } \\
Variable & Odds ratio $(\mathbf{9 5} \% \mathbf{C I})$ & $\boldsymbol{P}$-value \\
Age & $1.637(0.728-3.681)$ & 0.233 \\
Educational level & $1.050(0.715-1.540)$ & 0.804 \\
ADHD & $0.958(0.116-7.882)$ & 0.968 \\
Oppositional defiant & $1.190(0.062-22.738)$ & 0.908 \\
$\quad$ disorder & $0.686(0.034-13.954)$ & 0.806 \\
Conduct disorder & $72.743(6.521-811.412)$ & $<0.001$ \\
Self-injury behaviours & $2.337(0.402-13.587)$ & 0.345 \\
Tobacco use & $19.927(1.246-318.742)$ & 0.034 \\
Major depressive disorder &
\end{tabular}

$\mathrm{Cl}=$ confidence interval.

$A D H D=$ attention deficit hyperactivity disorder .

our results with. However, we are now undertaking another study on the prevalence of psychiatric disorders among a sample of adolescents in the community. Finally, as previous studies, it is a cross-sectional study and so a causal relationship between psychiatric disorders and imprisonment cannot be inferred.

Despite these limitations, this is the first study from a non-Western country that included so many different psychiatric disorders, using a semi-structured instrument with tested validity, reliability, sensitivity and specificity with the respondents being interviewed face to face. In addition, both of psychiatric disorders and subsyndromes were examined.

\section{Conclusion}

In conclusion, our findings show that the prevalence of psychiatric disorders was very high among the incarcerated adolescents. This suggests that all adolescents in the juvenile justice system should be screened for psychiatric disorders, and those with disorders should receive treatment to manage their condition both in prison and after their release from prison.

\section{Acknowledgements}

We thank the participants and the authorities of the prison. This research was funded in part by a grant from the Chancellor of Research Affairs of Shiraz University of Medical Sciences. All the results and comments expressed here are those of the authors and do not necessarily represent the official position or policy of the Department of Justice or university.

\section{References}

1. Fazel S, Doll H, Langstrom N. Mental disorders among adolescents in juvenile detention and correctional facilities: a systematic review and metaregression analysis of 25 surveys. Journal of the American Academy of Child and Adolescent Psychiatry, 2008, 47:1010-9.

2. Vreugdenhil $\mathrm{C}$ et al. Psychiatric disorders in a representative sample of incarcerated boys in the Netherlands. Journal of the American Academy of Child and Adolescent Psychiatry, 2004, 43:97-104.

3. Teplin LA et al. Psychiatric disorders in youth in juvenile detention. Archives of General Psychiatry, 2002, 59:1133-1143.

4. Ulzen TP, Hamilton $\mathrm{H}$. The nature and characteristics of psychiatric comorbidity in incarcerated adolescents. Canadian Journal of Psychiatry, 1998, 43:57-63.

5. Rogers KM et al. Conditions associated with identification of mentally ill youths in juvenile detention. Community Mental Health Journal, 2006, 42:25-40.

6. Gosden NP et al. Prevalence of mental disorders among 15-17-year-old male adolescent remand prisoners in Denmark. Acta Psychiatrica Scandinavica, 2003, 107:102-110.

7. Assadi SM et al. Psychiatric morbidity among sentenced prisoners: prevalence study in Iran. British Journal of Psychiatry, 2006, 188:159-164.

8. Rawal P et al. Racial differences in the mental health needs and service utilization of youth in the juvenile justice system. Journal of Behavioral Health Services \& Research, 2004, 31:242-254.

9. Yoshinaga $\mathrm{C}$ et al. Prevalence of post-traumatic stress disorder in incarcerated juvenile delinquents in Japan. Psychiatry and Clinical Neurosciences, 2004, 58:383-388.

10. Steiner H, Cauffman E, Duxbury E. Personality traits in juvenile delinquents: relation to criminal behavior and recidivism.
Journal of the American Academy of Child and Adolescent Psychiatry, 1999, 38:256-262.

11. Ghanizadeh A, Mohammadi MR, Yazdanshenas A. Psychometric properties of the Farsi translation of the Kiddie Schedule for Affective Disorders and Schizophrenia-Present and Lifetime Version. BMC Psychiatry, 2006, 6:10.

12. The Diagnostic and Statistical Manual of Mental Disorders, 4th ed. (DSM-IV). Arlington, VA, American Psychiatric Association, 2000.

13. Ghanizadeh A. Psychiatric comorbidity differences in clinicreferred children and adolescents with ADHD according to the subtypes and gender. Journal of Child Neurology, 2009, 24:679-684.

14. Ghanizadeh A, Mohammadi MR, Moini R. Comorbidity of psychiatric disorders and parental psychiatric disorders in a sample of Iranian children with ADHD. Journal of Attention Disorders, 2008, 12:149-155.

15. Vermeiren R, De Clippele A, Deboutte D. A descriptive survey of Flemish delinquent adolescents. Journal of Adolescence, 2000, 23:277-285.

16. Andrade RC, Silva VA, Assumpcao FB Jr. Preliminary data on the prevalence of psychiatric disorders in Brazilian male and female juvenile delinquents. Brazilian Journal of Medical and Biological Research, 2004, 37:1155-1160.

17. Chae PK, Jung HO, Noh KS. Attention deficit hyperactivty disorder in Korean juvenile delinquents. Adolescence, 2001, 36:707-725.

18. Ghanizadeh A, Bahredar MJ, Moeini SR. Knowledge and attitudes towards attention deficit hyperactivity disorder among elementary school teachers. Patient Education and Counseling, 2006, 63:84-88. 
19. Ghanizadeh A, Zarei N. Are GPs adequately equipped with the knowledge for educating and counseling of families with ADHD children? BMC Family Practice, 2010, 11:5.

20. Ghanizadeh A, Shams F. Children's perceived parent-child relationships and family functioning in attention-deficit/hyperactivity disorder. Child \& Family Behavior Therapy, 2007, 29:1-11.

21. Satterfield JH, Schell A. A prospective study of hyperactive boys with conduct problems and normal boys: adolescent and adult criminality. Journal of the American Academy of Child and Adolescent Psychiatry, 1997, 36:1726-1735.

22. Satterfield JH et al. A 30-year prospective follow-up study of hyperactive boys with conduct problems: adult criminality. Journal of the American Academy of Child and Adolescent Psychiatry, 2007, 46:601-610.
23. Plattner B et al. Suicidality, psychopathology, and gender in incarcerated adolescents in Austria. Journal of Clinical Psychiatry, 2007, 68:1593-1600.

24. Ruchkin VV et al. Suicidal ideations and attempts in juvenile delinquents. Journal of Child Psychology and Psychiatry, and Allied Disciplines, 2003, 44:1058-1066.

25. Brunner R et al. Prevalence and psychological correlates of occasional and repetitive deliberate self-harm in adolescents. Archives of Pediatrics \& Adolescent Medicine, 2007, 161:641-649.

26. Mohammadi MR et al. Suicidal attempt and psychiatric disorders in Iran. Suicide \& Life-Threatening Behavior, 2005, 35:309316.

\section{Mental health and development: targeting people with mental health conditions as a vulnerable group}

Mental health and development: targeting people with mental health conditions as a vulnerable group is a call to action to all development stakeholders - governments, civil society, multilateral agencies, bilateral agencies, global partnerships, private foundations, academic and research institutions - to focus their attention on mental health.

The report presents compelling evidence that persons with mental and psychosocial disabilities are a vulnerable group but continue to be marginalized in terms of development aid and government attention. It makes the case for reaching out to this group through the design and implementation of appropriate policies and programmes and through the inclusion of mental health interventions into broader poverty reduction and development strategies. The report also describes a number of key interventions which can provide a starting point for these efforts. By investing in persons with mental and psychosocial disabilities, development outcomes can be improved.

Further information about this and other WHO publications is available at: http://www.who.int/publications/en/ 